\title{
Stock Market Volatility Using GARCH Models: Evidence from South Africa and China Stock Markets
}

\author{
Priviledge Cheteni \\ University of Fort Hare, South Africa \\ 200909553@ufh.ac.za
}

\begin{abstract}
This study looks into the relationship between stock returns and volatility in South Africa and China stock markets. A Generalized Autoregressive Conditional Heteroscedasticity (GARCH) model is used to estimate volatility of the stock returns, namely, the Johannesburg Stock Exchange FTSE/JSE Albi index and the Shanghai Stock Exchange Composite Index. The sample period is from January 1998 to October 2014. Empirical results show evidence of high volatility in both the JSE market, and the Shanghai Stock Exchange. Furthermore, the analysis reveals that volatility is persistent in both exchange markets and resembles the same movement in returns. Consistent with most stock return studies, we find that movements of both markets seem to take a similar trajectory.
\end{abstract}

Keywords: GARCH, ARCH effect, JSE index, Shanghai Stock Exchange Composite Index

\section{Introduction}

In financial markets, volatility forecasting is important in gauging the riskiness of an investment. Most options for pricing in stock markets rely on a volatility parameter. Furthermore, volatility is further used in portfolio management. Option traders, portfolio managers and other traders are more concerned with forecasting, and having accurate forecast can help them produce higher earnings or reduce risk in their investments. Usually in financial time series, there are periods where volatility is higher than in other periods. Nevertheless, a movement that has been observed is that volatility tends to increase during economic disturbances such as recessions, financial crises, and oil crises. Volatility is defined as the degree at which stock values or share price changes in the stock market. Poon \& Granger (2005) refers to volatility as the spread of likely outcomes of an uncertain variable. Basically, volatility is linked to risk, although the two are different. The former indicates insecurity, and the later represents an unwanted outcome. Thus, volatility estimation has been at the cutting edge in a number of economic systems as a growth rate estimator. Levine (1991) stated that stock markets through the removal of impulsive liquidation of capital invested by firms accelerate economic development, which in turn raises firm liquidity and productivity. Over the decades, stock markets have been increasingly linked to national economies through capital flows, international trade, foreign direct investments, and advancement in technology (Chan et al., 1997).

Theoretical grounding of stock return volatility dates back to Black (1976) theory, which states that stock return volatility, is mainly caused by leverage effects. In other words, a decline in a firm's equity holding other things constant increases the debt/equity ratio of the firm, thus, inherently increasing its riskiness. Lack of conclusiveness in stock market returns has led to the founding of a number of models measuring leverage effects such as the GARCH. In general, volatility is important in the forecast of financial market volatility. Secondly, stock market volatility is a cause of interest to policy makers because the uncertainty in the stock market affects growth prospects, and creates insecurity, and in extreme cases, it acts as a barrier to investing (Raju \& Ghosh, 2004). For example, the stock market collapse that took place in 1997 led to a decline in consumer spending in the United States. Thus, volatility can be regarded as a constraining factor through its effects on consumer expenditure and business expenditure. Therefore, consistent volatility can be a reflection of underlying economic problems. The more stable the prices are, the better and more efficient would be the pricing of securities, leading to an efficient allocation of resources.

The introduction of Autoregressive Conditional Heteroscedasticity model (ARCH) by Engle (1982) and Generalized ARCH model later called GARCH by Bollerslev (1986) contributed to advances in financial econometric modelling. These exemplars have been popular because of their capability to capture financial time series volatility clustering. Franses and Van Dijk (1996) noted that GARCH models could take care of time varying volatility over long periods, hence, providing a very good sample estimate. A number of studies have attempted to explain the occurrence or foresee the movements within the stock market in order to test if the efficient market hypothesis holds. This means a number of studies have been devoted to examining if 
whether stock prices fluctuates excessively due to changes in fundamentals or some factors such as bubbles, incomplete information to name a few. One study to note was done by Chen, Roll, and Ross (1986) when they tried to explain the stock price volatility using changes in fundamentals. One of the findings of the study was that, although stock market index explained a large portion of the stock returns variability, its effect or influence was weak in comparison to changes in economic variables. Hence, the conclusion was that stock returns are determined by economic factors.

In Africa, stock markets are mostly affected by inefficiency, lack of liquidity, capital constraint, small size, and protectionism. As a consequence, most studies investigating volatility in Africa focus on the biggest and most sophisticated stock markets, notable in countries like South Africa and Egypt. Nevertheless, subjects that have focused on the South African stock market are inconclusive on the persistence of volatility, or if whether the stock market reacts more to good or bad news. A study conducted by Hassan, Maroney, El Sady and Telfah (2003) found that ARCH and GARCH effects exist in African stock markets, with Nigeria and South Africa stock markets showing that politics has a significant impact on those markets. On the hand, Haque et al. (2004) found that there is no persistence of volatility in the South African stock market. However, Hassan et al. (2003) points that African stock market volatility increases with the good news because once good news appears, investors may flood in, thus, increasing volatility. On the contrary, Ogum (2002) claimed that negative shocks increase volatility in Africa major stock markets.

According to DSFin (2016), volatility signal opportunities for investors. For instance, in 2009, phases of high volatility were trailed by periods of excellent returns. Notwithstanding, in 2007, volatility indicators such as the volatility index (VIX) were all time low, not an indication of low risk, but calm before the storm. During volatility times in the market, there is a lot of negative news flow. As a consequence, most investors are prone to making emotional decisions regarding their investment. For example, during the first quarter of 2016 in South Africa (SA), Investec Asset Management saw 60 percent of domestic flows shift into offshore funds compared to the 40 percent in the prior quarter. On the other hand, Bloomberg (2016) reported that foreign investors began to turn back to the SA markets. This ensured an increase of stock of about US $\$ 136$ million in the same quarter. Given the recent developments in the Chinese stock markets, excessive financial market volatility can stem from macro financial development in China (De Bock \& de Carvalho, 2015). China is the biggest trading partner for South Africa with trade amounting to over US\$60 billion (DTI, 2016). Previous studies have compared the Johannesburg Stock Exchange (JSE) to other stock markets, for instance, Samouilha (2006) found a positive relationship between the domestic returns and international market equity volatility using the JSE and the London Stock Exchange indices. Similarly, De Camara (2011) found spill over volatility between the JSE and the New York Exchange (NYSE), although there was a unidirectional link between those markets volatility shocks. On the other hand, Duncan and Kabundi (2011) indicate that equity is the most significant source of volatility spill over. De Camara (2011) explored the volatility transmission between the JSE and the FTSE All Share Index in Asia, and finds a contagion between these marketplaces. In support, Chinzara and Aziakpono (2008) find volatility linkages between South Africa and major world stock markets in the period 1995-2007.

While volatility in developed stock markets has been comprehensively researched, little has been done in terms of volatility in developing stock markets. Bekaert and Wu (2000) presuppose that developing markets are marked by higher sample average returns, returns that are more predictable, higher volatility and low correlations with developed market returns. These differences may have implications for a number of interested parties such as investors, policy makers to name a few. This study takes a different approach by comparing the volatility in South Africa and the Chinese stock market, such a route has not been taken in literature. Thus, it attempts to close the literature gap by forecasting market volatility in one of the biggest economy in the world and comparing it to the largest economy in Africa in an effort to identify any similarities or differences, which may aid in the allocation of investment resources. At the same time identifying the likely implications of volatility in both stock returns in the aforementioned countries. This is a huge contribution to the body of knowledge and financial fields. In addition, considering that China is one of the world largest economies in the world, any slowdown or changes in its stock markets are expected to bring about spillover effects to other systematic economies, trading partners especially in the emerging economies. Hence, it would add more value to literature to interpret how the Chinese stock markets perform when compared to a small economy like South Africa, which is one of the biggest in Africa. Previous studies (Bali, 
2000; Shin, 2005; Floros, 2007; Samouilhan and Shannon, 2008; Olowe, 2009; Mishra, 2010) used augmented GARCH models to estimate volatility in stock markets. This study employs a basic GARCH model to estimate volatility clustering in both aforementioned markets. There is limited modification to the model used because the intention is to make a comparison of volatility clustering, as opposed to finding causality between the stock markets, a complex thing to do considering that China and South Africa are subject to different market forces. So, the primary purpose of this paper is estimate stock market volatility in South Africa and China stock markets.

The paper is organized as follows: Section 2 describes the data and methodology used, Section 3 discusses the empirical findings and interpretation of results, and Section 4 concludes the paper.

\section{Data and Methodology}

This study examines Africa's largest stock market along with the Chinese stock market. The sample used in this study consists of weekly national indexes representing market weighed price averages retrieved from the Johannesburg Stock Exchange and the Shanghai stock exchange. The national indices are built based on the same pattern and adjusted by the same formulae, making them comparable to one another. Each of the country indexes broadly represents stock composition in different countries. The study uses the Shanghai Stock Exchange Composite Index from the Shanghai Stock exchange; the second largest in Asia by market capitalization (Shanghai Stock Exchange, 2016). The Shanghai index is the most used weighed composite index that reflects the performance of the Shanghai Stock exchange. In South Africa, we use the FTSE/JSE Albi index a market capitalization weighted index composed of 99 percent of the total free float market capitalization of all listed companies on the Johannesburg Stock Exchange (Bloomberg, 2016). According to Chen et al. (1986) researchers are cautioned against using national stock indexes as exchange rate variations may heavily bias these indexes. However, considering that this study does not attempt any cross-country comparison in the analysis, the influence of these indexes makes them valuable for comparison or representative of national stock markets. The data we analyze in this paper are monthly-observed indexes for the stock markets in South Africa (JSE) and China. The data span is about 16 years, with the first observation being the month of January in 1998 and the last observation being October 2014. Data cleaning was done on the dataset by removing zero values for the South Africa public holidays, as well as in China.

The model: The ARCH and GARCH models are the most popular instruments for measuring volatility dynamics in financial time series. The GARCH model makes a current conditional variance dependent on lags of its previous variance. Nevertheless, one of the limitations is that it enforces symmetric responses of volatility to both negative and positive volatility market shocks (Bollerslev et al., 1994).

\section{GARCH (1.1) model}

$\sigma_{t}^{2}=w+\alpha_{1} \varepsilon_{t-1}^{2}+\beta_{2} \sigma_{t-1}^{2}$

Equation 1 is a function of variables with an error term. $\sigma_{t}^{2}$ (Conditional variance) is one period ahead of forecast variance based on past information. wis a constant term; $\varepsilon_{t-1}^{2}$ (ARCH term) is news about volatility from the previous period measured as a lag of squared residual from the mean equation. $\sigma^{2}{ }_{t-1}$ (GARCH term) is the last period forecast variance. The 1,1 in the GARCH refers to the presence of first order autoregressive GARCH term and the first order moving average ARCH term. An ARCH model is a special case of GARCH specification in form of GARCH $(0,1)$. Additionally, by adding the lagged $\varepsilon_{t}^{2}$ terms to both sides of the above equation and moving $\sigma_{t}^{2}$ to the right-hand side, the $\operatorname{GARCH}(1,1)$ model can be rewritten as an ARMA(1,1) process for the squared errors:

$\varepsilon_{t}^{2}=\alpha_{0}+\left(\alpha_{1}+\beta_{1}\right) \cdot \varepsilon_{t-1}^{2}+v_{t}-\beta_{1} \cdot v_{t-1}$

where $v_{t}=\varepsilon_{t}^{2}-\sigma_{t}^{2}$.

$\operatorname{GARCH}(1,1)$ is termed stationary in variance if $\alpha_{1}+\beta_{1}<1$. This is the case were the unconditional variance of $\varepsilon_{t}$ is constant and given by the following equation:

$\operatorname{var}\left(\varepsilon_{t}\right)=\frac{\alpha_{0}}{1-\left(\alpha_{1}+\beta_{1}\right)}$

The non-stationarity in variance is the case where $\alpha_{1}+\beta_{1} \geq 1$ and the unconditional variance of $\varepsilon_{t}$ is not defined. Moreover, $\alpha_{1}+\beta_{1}=1$ is known as a unit root in variance, termed as IGARCH. In this paper, two 
2historic time series data sets were analysed to investigate the existence of volatility clustering between the JSE/ALBI Index and the Shanghai Stock Exchange Composite Index. Normality in the data was evaluated by the Jaque Bera, and stationarity with the Augmented Dickey Fuller (ADF) test.

Diagnostic Tests: We start with an inspection of the daily returns. The results in Figure 1 show that the movement of stock returns is both positive and negative. It can be noted that the returns fluctuate around the mean value, but close to zero. Larger fluctuations tend to cluster together followed by periods of calmness. This is the general norm with stock returns. Fama (1990) noted that stock returns tend to fluctuate thereby exhibiting volatility clustering, where large returns are usually complimented by small returns. To illustrate, Figure 1 plots the monthly stock returns of the JSE All index and Shanghai Stock Exchange Composite Index from 1998 -2014. The returns are articulated in percentage and are constantly compounded. Figure 1 illustrates that the returns do not exhibit independent and identically distributed (i.i.d). Volatility clusteringwas higher in the period of 2008-2009 when there was a global financial crisis. Cheteni (2014) noted that the JSE index was not i.i.d during the 2008-2009 period, and the returns were non linear and dependent. Similarly, Bollerslev, Engle and Nelson (1994) found that stock returns usually reflect a ten dency of not being i.i.d.More often than not, it can be summed up that when stock volatility changes, stock returns tend to move the same way as well. In addition, returns tend to be leptokurtic as shown in Figure 1 kernel density graphs, were both returns show a distribution of having high peaks and having fat tails.

Figure 1: Stock returns from 1998-2014

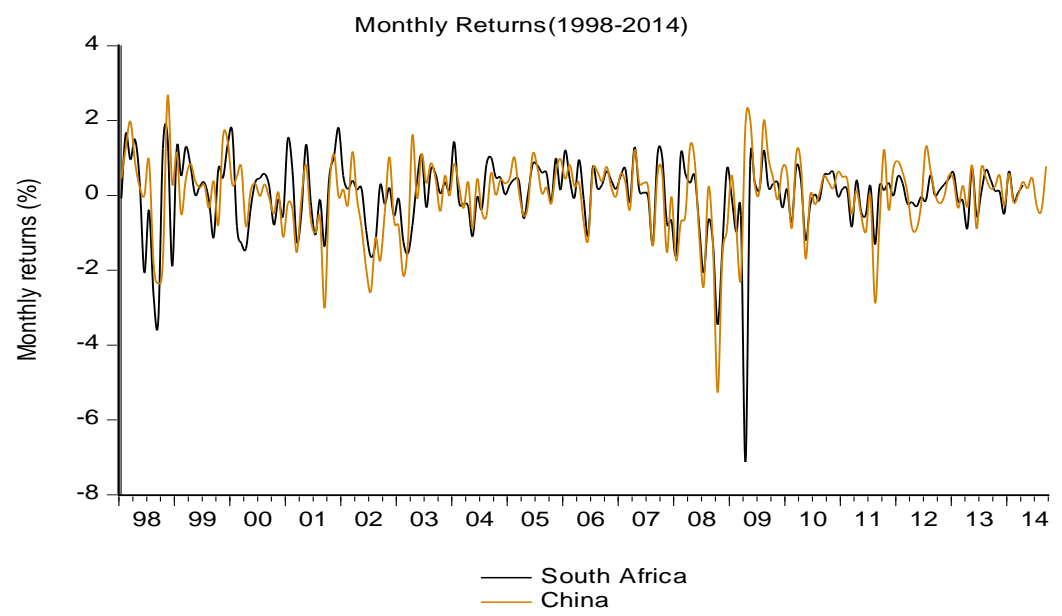

Source: Researcher own data

Normality Tests: Figure 2 and 3 show the descriptive statistics for the stock returns for the countries under study. The data from all countries shows that skewness statistics are negative, indicating that the returns are not asymmetric and the distribution has a long left tail. In addition, the kurtosis is way over 3 suggesting that the underlying time series data is heavily tailed and sharply peaked when compared to a normal distribution. In Figure 2 the descriptive statistics show that the South African market observed mean monthly return of $0.078 \%$, way higher than the Chinese market which had $-0.147 \%$. The volatility measured by the standard deviation shows that the South African market had a deviation of $1 \%$ and the Chinese market had $0.99 \%$ which was almost similar. This implies that both markets are almost similar in volatility. The more the market is volatility, the higher the chances of getting high rates of returns but with more risk. The Jarque -Bera statistics rejects the normality assumption. Hence, confirming the general norm that stock returns are not normally distributed and skewed. 
Figure 2: Normality Test FTSE/JSE Index

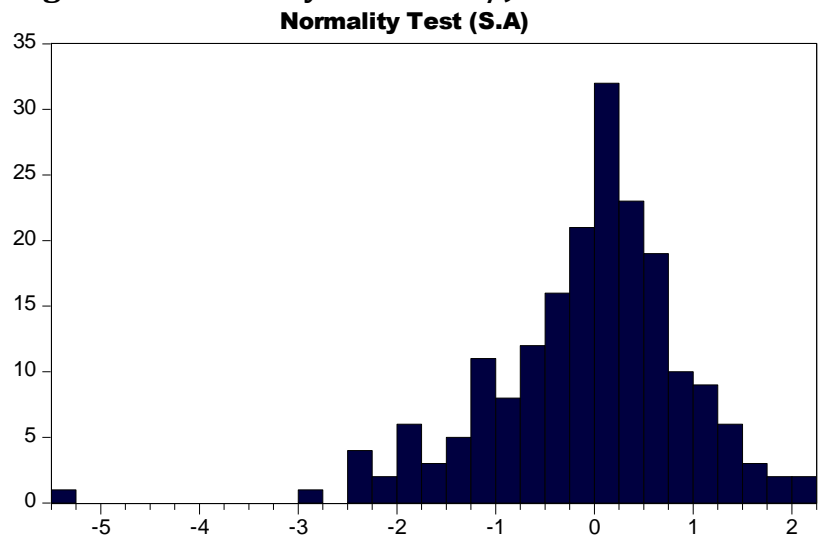

Series: Standardized Residuals

Sample 1998M01 2014M04

Observations 196

Mean

Maximum 2.168399

Minimum $\quad-5.255508$

Std. Dev. $\quad 1.001466$

Skewness $\quad-1.021321$

Kurtosis $\quad 6.114391$

Jarque-Bera 113.2865

Probability $\quad 0.000000$

Figure 3: Normality Test Shanghai Stock Exchange Composite Index

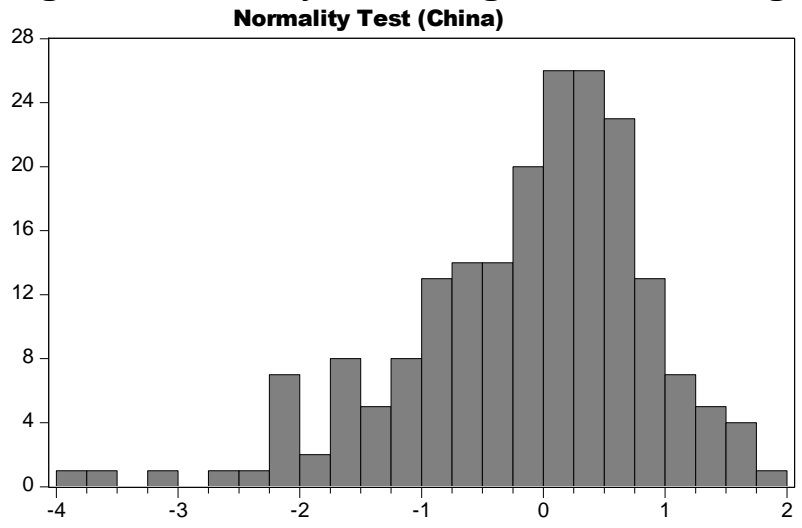

Series: Standardized Residuals Sample 1998M01 2014M09

Observations 201

Mean $\quad-0.147411$

Median $\quad 0.049357$

Maximum 1.855329

Minimum $\quad-3.821703$

Std. Dev. $\quad 0.991510$

Skewness $\quad-0.864606$

Kurtosis $\quad 4.047314$

Jarque-Bera 34.22899

Probability $\quad 0.000000$

Source: Researcher own data

Unit root test: We conduct an Augmented Dickey Fuller (ADF) test in order to test for stationarity. The results from the test show that the time series data is stationary. The ADF test statistics reject the null hyphotheis that there is an existence of a unit root in the return data series. The ADF statisticis less than the critical values.The null hypothesis is rejected against the one sided alternative ifthe test statistics are less than the critical. In this case, the test rejects the null hypothesis of a unit root in time series in all three levels of significance.Consequently, we reject that the time series is non stationary.

Table 1: ADF results

\begin{tabular}{lll}
\hline & South Africa JSE index & $\begin{array}{l}\text { Chinese } \\
\text { Exchange Composite Index }\end{array}$ \\
\hline ADF statistics & -11.52722 & -10.67004 \\
& $0.0000^{*}$ & $0.0000^{*}$ \\
Critical values: & & \\
1\% level & -3.463924 & -3.463067 \\
5\% level & -2.876200 & -2.875825 \\
10\% percent & -2.574663 & -2.574462 \\
*MacKinnon (1996) one-sided p-values. & \\
\hline
\end{tabular}

Source: Researcher own data

Arch test: Both the $F$ version and $L M$-Statistic are statistically significant, suggesting the presence of ARCH in the data series and stock returns. Both the FTSE/JSE index and the Shanghai Stock Exchange Composite Index produced similar results. The test was carried using the lag order of $q=5$. Table 2 presents the results of these tests. 
Table 2: ARCH Test results

\begin{tabular}{lll}
\hline & South Africa (JSE index) & $\begin{array}{l}\text { Chinese } \\
\text { Exchange Composite Index) }\end{array}$ \\
\hline ARCH-LM Test & 1.268447 & 4.626889 \\
Prob. Chi-square & 0.00381 & 0.00631 \\
F-Statistics & 0.247329 & 0.918703 \\
Prob (F-statistic) & 0.09407 & 0.04700 \\
\hline
\end{tabular}

Source: Researcher own data

\section{Empirical Results}

In this section, we report the results of the GARCH model. The coefficients on both the lagged squared residual and lagged conditional variance in the Variance Equation are highly statistically significant. Furthermore, the sum of the ARCH and GARCH $(\alpha+\beta)$ coefficients of both the JSE and Shanghai Stock Exchange Composite Index is very close to one. This shows that volatility shocks are quite relentless in both stock markets. This is normally the case in high frequency financial data. See Table 3 for a summary of the results. Large sums of coefficients imply that large positive and negative return will lead to future forecast of the variance to be a high for a prolonged period. The variance intercept ' $c$ ' is larger than the ARCH parameter for the JSE index. However, for the Shanghai Stock Exchange Composite Index the intercept term 'c' is over 2 which are way higher than expected and the ARCH term is 0.52 , which is also more eminent than the GARCH term which is 0.46 .Therefore, the GARCH model implies that conditional volatility is persistent in both stock markets.

Table 3: GARCH (1.1) Results

South Africa (JSE index) Chinese (Shanghai Stock Exchange

Composite Index)

\begin{tabular}{|c|c|c|c|c|c|c|}
\hline \multicolumn{7}{|l|}{ Mean Equation } \\
\hline Variable & Coefficient & z-Statistic & Prob. & Coefficient & z-Statistic & Prob. \\
\hline $\mathrm{C}$ & 1.386713 & 4.335621 & $0.0000^{* * *}$ & 0.942534 & 3.534023 & $0.0004^{* * *}$ \\
\hline \multicolumn{7}{|l|}{ Variance Equation } \\
\hline $\mathrm{C}$ & 0.477422 & 1.007453 & 0.3137 & 3.063705 & 1.984380 & $0.0472^{* *}$ \\
\hline $\operatorname{RESID}(-1)^{\wedge} 2(\alpha)$ & 0.220842 & 3.238921 & $0.0012^{* * *}$ & 0.520904 & 3.383880 & $0.0007^{* * *}$ \\
\hline $\operatorname{GARCH}(-1) \quad(\beta)$ & 0.794372 & 15.47958 & $0.0000^{* * *}$ & 0.469882 & 3.590656 & $0.0003^{* * *}$ \\
\hline$\alpha_{1}+\beta_{1}$ & 1.015214 & & & 0.990786 & & \\
\hline R-squared & -0.009678 & & & & -0.024072 & \\
\hline Sum squared resid & 6397.844 & & & & 5171.333 & \\
\hline Log likelihood & -593.3016 & & & & -589.1704 & \\
\hline Durbin-Watson stat & 1.615454 & & & & 1.425581 & \\
\hline
\end{tabular}

Note. ${ }^{* * *}$ Significant at $1 \%$ level; ${ }^{* *}$ Significant at $5 \%$ level;

Source: researcher own data

A larger value of $\beta$ suggests that the shocks of conditional variance takes long time to die out, hence, volatility is persistent. A mere presentation of such an event was recorded in the South Africa JSE stock market during the 2007-10 global financial crises, where volatility was high during the crisis. Pretorius and de Beer (2014) claim that during the same period, volatility transfer from China was at its lowest. However, the impact of the crisis took time to normalize in the stock market. As shown in Table 3, the JSE index had $\beta=0.7943$ compared to the Shanghai index were $\beta=0.4698$, meaning that the JSE is highly volatile than the Shanghai stock market because of persistent volatility. Yet, a low value error coefficient $(\alpha)$ suggests that large market surprises induce relatively small volatility. As illustrated in Table 3, the JSE had $(\alpha)=0.2208$ compared to the Shanghai with $(\alpha)=0.5209$. However, it shows that recent news $(\alpha)$ has more impact in the Chinese stock market than the South Africa market. This is in support to Pretorius and de Beer (2014) who pointed that volatility comovement between the South and China is not high. However, South Africa is more prone to high volatility emanating from states such as Germany, the US, Brazil and the UK. 
Alternatively, the coefficient $(\beta)$ represents past news and it is higher in the South African market than the Chinese market, suggesting that old news has an influence in both markets. Although much impact is felt in the South African market, compared to the Chinese stock market. As mentioned by the European Economic Forecast (2016), financial volatility rose across emerging markets throughout the past three years. This has prompted investors to withdraw from equity and bond markets in the process depressing exchange rates. This has been evident in South Africa, as noted by Investec Asset Management (2016) were 60 percent of domestic flows were shifted to offshore funds leading to the subverting of the South African currency. Unpredictability in the Chinese stock market has an implication for commodity prices, world trade and spill over to other areas, which constitutes downside risks (European Economic Forecast, 2016). Shanghai Composite index wiped about US\$ 3 trillion in market capitalization leading to a fall in investments. Nevertheless, the South African economy is expected to feel this effect in the coming two years as China transitions its economy from investment spending to consumer expenditure. The implications of stock volatility in the Chinese market are yet to be felt in the South African economy, as the South African currency continues to fluctuate when good or bad news is reported.

Standard deviations of return: Standard deviation is a commonly used measure for stock market volatility. The standard deviation measures dispersion of the returns, therefore, the larger the standard, the higher the chance of negative or positive returns. Figure 4 and 5 plots show the standard deviations of the monthly returns of the JSE and Shanghai stocks from 1998-2014. The 12 monthly returns are used to calculate the standard deviation. From the plots it can be determined that stock return standard deviations are around 4 percent per month. This implies that most returns were between 8 and -8 percent per month. During the global financial crisis in 2008-2010, the standard deviation was over 16 percent per month, indicating that most returns were around 32 percent and -32 percent per month. Essentially, it can be noted that years with extreme returns have high standard deviations. Since 2012 it can be seen that returns have not shown unusually high volatility, suggesting that there is stability in the stock markets. Historical series of standard deviations points that stock returns have been less volatile recently. This can be assigned to two scenarios. To begin with, traders who do not have correct information about the value of the securities trade in the future markets. This creates temporary prices, which are amplified. Instead, new information may be affecting future contract costs; therefore, contracts may be having lower transaction costs leading to pricing of funds simultaneously. However, a number of factors may be affecting volatility; these factors include economy condition, recessions, financial leverage, personal leverage and operating leverage to name a few.

Figure 4: JSE index standard deviation

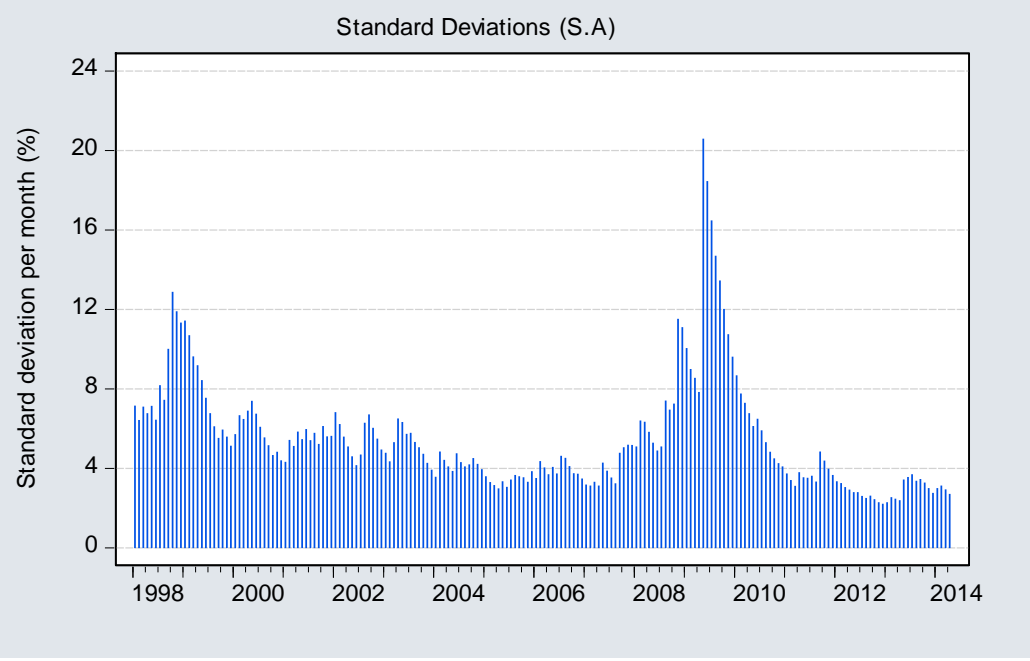




\section{Figure 5: Shanghai Stock Exchange Composite Index standard deviation}

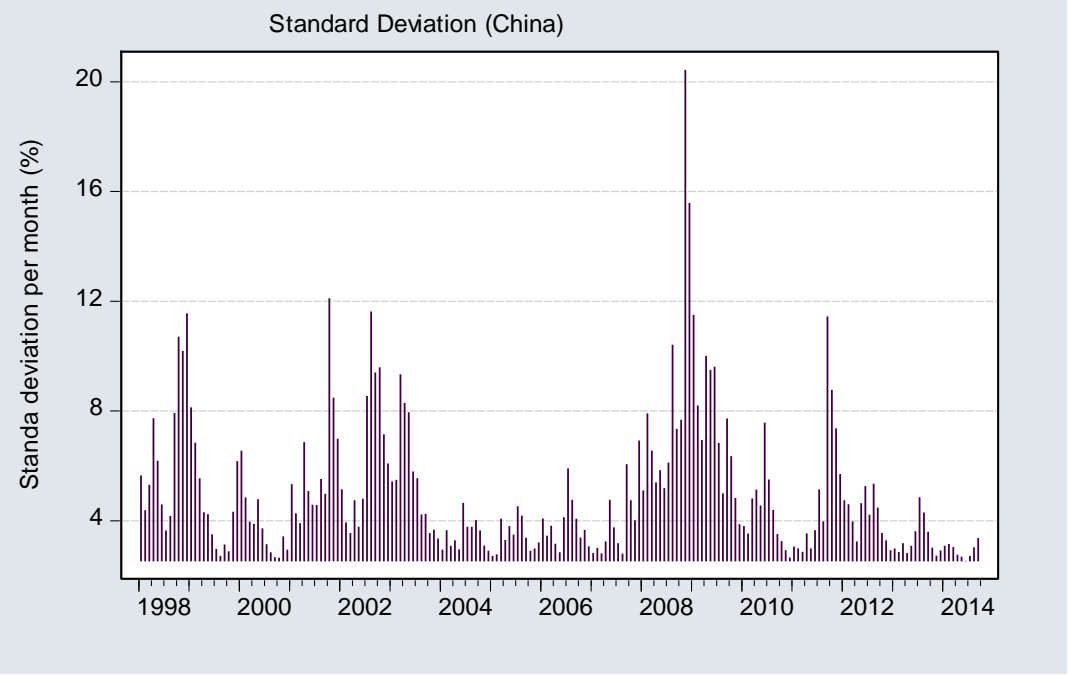

Source: Researcher own data

In both markets, there are periods of time where returns hardly change (market tranquility) and where changes in returns are followed by large changes (market turbulence). In South Africa, stock returns usually respond to the volatility of the South Africa Rand because of its sensitivity to bad or good news.

\section{Conclusion and Recommendations}

This paper focused on similarities and differences in volatility clustering in South Africa and the Chinese stock markets. It also presented some valuable empirical results that partly identified the causes of stock return volatility. It did not try to measure volatility with other methods such as EGARCH, IGARCH, but it was mainly grounded on the GARCH and ARCH models. The paper utilized the GARCH $(1,1)$ model since the objective was to estimate the volatility of financial time series and to test the existence of dependence in stock returns. The model is sufficient to capture the dynamics of the stock returns, particularly the volatility clustering and leptokurtic features. We found that the South African market and the Chinese market exhibiting the same features in terms of volatility clustering. The most plausible cause for such a similarity may be that there is more trading between these two economic systems. The paper did not try to identify all the possible causes of this phenomenon between the two stock exchanges because the model used cannot fully capture the aspect of leverage and asymmetry in the stock returns. Thus, a model measuring those two aspects may contribute a better understanding between the two stock markets. Future research can focus on identifying the underlying linkages between the two stock markets. This signifies that further research can specialize on other methods such as multivariate approaches in identifying the linkages between the two stock markets. On the other hand, researchers can use data from other countries trading extensively with South Africa, such as India, and Russia to study the performance of stock markets in those countries in comparison to the South African stock market.

\section{References}

Bali, T. (2000). Testing the empirical performance of stochastic volatility models of the short-term interest rate. Journal of Financial and Quantitative Analysis, 35(2), 191-215.

Bekaert, G. \& Wu, G. (2000). Asymmetric volatility and risk in equity markets. Review of Financial Studies, 13, $1-42$.

Bollerslev, T. (1986). Generalized Autoregressive Conditional Heteroskedasticity. Journal of Econometrics, 31(3), 307-327.

Bollerslev, T., Engle, R. F. \& Nelson, D. B. (1994). ARCH Models, in R.F. Engle and D. McFadden (eds.), Handbook of Econometrics, 4, 2959-3038. 
Black, F. (1976). Studies of Stock Price Volatility Changes, Proceedings of the Business and Economics Section of the American Statistical Association, 177-181.

Bloomberg. (2016). Stock Indexes. Retrieved from www.bloomberg.com

Chan, L., Jegadeesh, N. \& Lakonishok, J. (1997). Momentum strategies. Journal of Finance, 51, 1681-1713.

Chen, N., Roll, R. \& Ross, R. (1986). Economic Forces and the Stock Market. Journal of Business, 59, 383-403.

Cheteni, P. (2014). Non-Linearity Behavior of the ALBI Index: A Case of Johannesburg Stock Exchange in South Africa. Mediterranean Journal of Social Sciences, 5(9), 183-187.

Chinzara, Z. \& Aziakpono, M. J. (2008). Dynamic returns linkages and volatility transmission between South African and world major stocks markets. Studies in Economics and Econometrics, 33(3), 69-94.

De Bock, R. \& de Carvalho, F. (2015). The Behavior of Currencies during Risk-off Episodes. Journal of International Money and Finance, 53, 218- 234.

De Camara, R. M. (2011). The Price and Volatility Transmission of International Financial Crises to the South African Equity Market. Master Dissertation, North-West University.

DSFin. (2016). The first 2 weeks of April 2016. Retrieved from: www.dsfin.co.za

Duncan, A. S. \& Kabundi, A. (2011). Volatility spillovers across South African asset classes during domestic and foreign financial crises. Economic Research Southern Africa, Working Paper 202.

Engle, R. F. (1982). Autoregressive Conditional Heteroscedasticity with Estimates of Variance of United Kingdom Inflation. Econometrica, 50(4), 987-1008.

Fama, E. (1990). Stock returns, Expected Returns, and Real Activity. Journal of Finance, 3, 1189-1108.

Floros, C. (2007). The use of GARCH models for the calculation of Minimum Capital Risk Requirements: International Evidence. International Journal of Managerial Finance, 3(4), 360-371.

Franses, P. H. \& Van Dijk, D. (1996). Forecasting stock market volatility using (non-linear) GARCH models. Journal of Forecast, 15, 229-235.

Haque, M., Hassan, M. K., Maroney, N. \& Sackley, W. H. (2004). An empirical examination of stability, predictability, and volatility of Middle Eastern and African emerging stock markets. Review of Middle Economics and Finance, 2(1), 19-42.

Hassan, M. K., Maroney, N. C., El Sady, H. M. \& Telfah, A. (2003). Country risk and stock market volatility, predictability, and diversification in the Middle East and Africa. Economic Systems, 27, 63-82.

Levine, R. (1991). Stock Markets, Growth, and Tax Policy. Journal of Finance, 46(4), 1445-65.

Mishra, P. K. (2010). A GARCH Model Approach to Capital Market Volatility: The Case of India. Indian Journal of Economics and Business, 9(3), 631-641.

Ogum G. (2002). An analysis of asymmetry in the conditional mean returns: Evidence from three sub-Saharan Africa emerging equity markets. The African Finance Journal, 4(1), 78-82.

Olowe, R. A. (2009). Modelling Naira/Dollar Exchange Rate Volatility: Evidence from GARCH and Asymmetric Models. International Review of Business Research Papers, 5(3), 377-398.

Poon, S. H. \& Granger, C. W. J. (2005). Practical issues in forecasting volatility. Financial Analyst Journal, 61(1), $45-65$.

Pretorius, A. \& De Beer, J. (2014). Comparing the South African stock markets response to two periods of distinct instability - the 1997-98 East Asian and Russian and the recent global financial crisis. International Business \& Economics Research Journal, 13(3), 427-442.

Raju, M. T. \& Ghosh, A. (2004). Stock market volatility-An International Comparison, Securities and Exchange Board of India.

Samouilhan, N. L. (2006). The Relationship between International Equity Market Behavior and the JSE. South African Journal of Economics, 74(2), 248-260.

Samouilhan, N. L. \& Shannon, G. (2008). Forecasting Volatility on the Johannesburg Stock Exchange. Investment Analysts Journal, 67, 19-28

Shin, J. (2005). Stock Returns and Volatility in Emerging Markets. International Journal of Business and Economics, 4(1), 31-43. 